\title{
Mechanical and Flame-Retardant Properties of Nanocomposite Based on Epoxy Resin Combined with Epoxidized Linseed Oil, Which Has the Presence of Nanoclay and MWCNTs
}

\author{
Tuan Anh Nguyen \\ Faculty of Chemical Technology, Hanoi University of Industry (HaUI), No. 298 Cau Dien, North District Tu Liem, \\ Hanoi, Vietnam \\ Correspondence should be addressed to Tuan Anh Nguyen; anhnt@haui.edu.vn
}

Received 9 May 2019; Revised 30 December 2019; Accepted 16 January 2020; Published 5 March 2020

Academic Editor: Sevgi Kolaylı

Copyright (C) 2020 Tuan Anh Nguyen. This is an open access article distributed under the Creative Commons Attribution License, which permits unrestricted use, distribution, and reproduction in any medium, provided the original work is properly cited.

One of the main disadvantages of epoxy resins is brittleness and flammability, which is one of the biggest threats and the reason for limiting advanced applications. In this study, Epikote 240 (EP) epoxy resin was plasticized with epoxidized flaxseed oil (ELO) at different concentrations (EP/ELO ratios 95/5; 90/10; 85/15; 80/20; 75/25). Then, nanoclay additives and MWCNTs are simultaneously dispersed into the EP/ELO blend by using ultrasonic vibration. The dispersion of ELO and nanoclay additives (nanoclay and MWCNTs) in epoxy resin is observed by using the scanning electron microscope in combination with the XRD method. The effect of ELO, nanoadditives on mechanical properties, and flame retardants is assessed by tensile strength, flexural strength, compressive strength, impact resistance, UL 94HB method, and limiting oxygen index. Experimental results have shown that the mixing ratio of $90 / 10 \mathrm{w} / \mathrm{w}$ is the ratio for good compatibility, high mechanical properties, and fire retardation compared with other ratios. When adding MWCNTs as well as nanoclay I.30E to Epikote 240 epoxy, the mechanical strength and fire resistance have changed greatly: tensile strength of $85.45 \mathrm{MPa}$, flexural strength of $116.32 \mathrm{MPa}$, compressive strength of 189.25 MPa, impact resistance Izod of $24.37 \mathrm{~kJ} / \mathrm{m}^{2}$, and fire resistance reached at $\mathrm{V} 1$.

\section{Introduction}

Epoxy flaxseed oil is one of the biological polymers, and it is more advantageous compared with petroleum-based polymers, due to its eco-friendly nature and biodegradability. Therefore, biopolymers are used to replace synthetic polymers derived from petroleum oil. The development of biodegradable polymers using "green materials" is important [1-5]. Vegetable oil is a valuable resource in the production of biodegradable polymers. Due to the low cost and environmental advantages of epoxidized vegetable oils, they have been synthesized for use as a new biodegradable polymer by many researchers [6-9]. Bisphenol $\mathrm{F}$ based epoxy resin (DGEBF) has been replaced by epoxyzed flaxseed oil with a content of $50 \%$ by weight, and $5 \%$ by weight of nanoclay was added [10]. The mixture including DGEBF and ELO was treated with methyl tetrahydrophthalic anhydride (MTHPA) as a curing agent and 1-methylimidazole as an accelerator. As a result, with the presence of ELO, the glasstransition temperature (Tg) of DGEBF decreased and decreased sharply when adding nanoclay. When using curing agents related to amine group, the $\mathrm{Tg}$ increased due to the limiting of the transition of the fractions caused by the borders between organic phase (amine) and inorganic phase (clay). Alam et al. reported the study on adding ELO into polylactic acid (PLA) with presence of MWCNTs to decrease $\mathrm{Tg}$ and improved the mechanical properties of materials. In this study, such various amounts of ELO as 5,10 , and $15 \%$ by weight were used and the decrease of $\mathrm{Tg}$ as well as the increase of the plasticity of PLA were proved. However, when adding MWCNTs, Tg of materials got slightly increased. It is caused by the adhesion and cross-links between MWCNTs and resin [10].

ELO and nanoclay were added into epoxy resin for the first time to improve the mechanical and retardant properties of materials which was reported by Das and 
Karak in 2009 with a study on retardant properties of epoxy/nanoclay nanocomposite based on vegetable oils. As a result, the tensile strength and hardness of materials were tripled. The limiting oxygen index (LOI) and UL 94 experiments proved that nanocomposite based on the vegetable oil Mesua ferrea $\mathrm{L}$ was be able to retard fire $[11,12]$. The above said data show that when adding ELO, which is a natural and eco-friendly oligomer, several properties of polymers were changed, for example, decrease in $\mathrm{Tg}$ and improvement in plasticity. However, studies on producing composite materials based on ELO with the presence of ELO are not enough, especially studies on fire-retardant properties and adding MWCNTs and nanoclay at the same time into epoxy resin. Nanoclay additives (nanoclay and MWCNTs) are also used simultaneously to enhance the mechanical and flame-retardant properties of nanocomposites based on epoxy $[13,14]$. However, at present, there have been no researches on manufacturing epoxy resin nanocomposites based on the synergies of three components: nanoclay, MWCNTs, and ELO. The goal of this work is to increase several mechanical properties of epoxy polymer material by mixing epoxidised linseed oil and epoxy resin and find the optimal mixing ratio. In this study, the flame retardants like antimony trioxide and chlorinated paraffins were combined with epoxy Epikote 240 resin/epoxidised linseed oil cured by diethylenetriamine (DETA) hardeners in order to increase the flammability and maintain the mechanical strength of this material. The combustion resistance and limiting oxygen index (LOI), UL 94 methods with transmission electron microscopy (FESEM), and XRD methods were used.

\section{Experimental}

2.1. Materials. Epoxy Epikote 240 (EP) resin was from Dow Chemicals (USA) with an epoxy group content of $24.6 \%$, Mw 5100-5400 mmol/kg, density $1.12 \mathrm{~g} / \mathrm{ml}$, and viscosity at $25^{\circ} \mathrm{C}$ : 007-1.1 Pa.s. Diethylenetriamine (DETA) was from Dow Chemincals (USA) with a density of $0.95 \mathrm{~g} / \mathrm{ml}$, boiling point $207^{\circ} \mathrm{C}$, and $\mathrm{Mw} 103$. Epoxidised linseed oil (ELO) is available commercially from a number of outlets and was obtained as Lankroflex E2447 from Akcros Chemicals Limited.

MWCNTs with a diameter of $40-45 \mathrm{~nm}$ and a length of around $3 \mu \mathrm{m}$ were provided by Showa Denko Japan Co. Chlorinated paraffin-S52 (CPs) was purchased from China and contained a maximum of $52 \%$ of chlorine. Antimony oxide (ATO) was received from China as fine white powder, was melted at $656^{\circ} \mathrm{C}$, and had a specific gravity of 5.7 . Antimony trioxide is over than $99.0 \%$, and the amount of antimony metal is approximately to be $83 \%$. The average size of fine powder antimony trioxide was found to be $1.5 \mu \mathrm{m}$. Nanomer ${ }^{\circledR}$ I.30E nanoclay (NanocorUSA) is a surfacemodified montmorillonite mineral which will disperse to nanoscale in epoxy resin systems. The dispersion creates a near-molecular blend commonly known as a nanocomposite. This new type of composite exhibits enhanced strength and thermal and barrier properties. I.30E is supplied as a white powder which disperses to particles so thin that they are nearly transparent in the resin matrix.

2.2. Preparation of Epoxy/Epoxidised Linseed Oil/MWCNTs/ Nanoclay Mixture. Epoxy Epikote 240 resin was mixed with epoxidised linseed following other ratios (Table 1) in $250 \mathrm{ml}$ round-bottomed three-neck flask, the mixture was stirred 1500 rounds/minute in 1 hour, and it had a thermal stability at $80^{\circ} \mathrm{C}$. The homogeneous mixture was cured by DETA at the room temperature in 24 hours, and then it was dried at $80^{\circ} \mathrm{C}$ in 3 hours. After 7 days, the mixture was analyzed and mechanical properties were measured.

MMT (2 wt $\%)$ and MWCNT (0.2 wt $\%)$ were dispersed in epoxy Epikote 240 resin (90 phr)/ELO (10 phr) and stirred at $3500 \mathrm{rpm}$ for $8 \mathrm{~h}$ (HS-100T, WiseStir, Korea). In order to break up the MWCNT bundles and disperse the additives, it was sonicated using an ultrasonic bath (Elmasonic S300 H, $37 \mathrm{kHz}$, Germany) for $6 \mathrm{~h}, 65^{\circ} \mathrm{C}[15]$.

2.3. Analysis. The curing level was determined by extracting with acetone in soxhlet in 24 hours.

The tensile strength was determined according to the ISO 178-1993 standard in INSTRON (USA) equipment with a crosshead speed $5 \mathrm{~mm} / \mathrm{min}$, temperature $25^{\circ} \mathrm{C}$, and humidity $75 \%$.

The flexural strength was determined according to the ISO 178-1993 standard in INSTRON (USA) equipment with a crosshead speed $5 \mathrm{~mm} / \mathrm{min}$, temperature $25^{\circ} \mathrm{C}$, and humidity $75 \%$. The compressive strength was determined according to the ISO 178-1993 standard in INSTRON (USA).

The Izod impact strength was determined according to the ASTM D265 standard in Tinius Olsen (USA) at a temperature $25^{\circ} \mathrm{C}$ and humidity $75 \%$.

The compressive strength was determined according to the ISO 178-1993 standard in INSTRON (USA) equipment with a crosshead speed $5 \mathrm{~mm} / \mathrm{min}$, temperature $25^{\circ} \mathrm{C}$, and humidity $75 \%$.

FE-SEM (Evacseq error codes, S-4800) was used to investigate the morphological effects of adding antimony trioxide and chlorinated paraffins to the epoxy resin. Every sample was sputter-coated with gold-palladium and placed under room vacuum to take FE-SEM images.

The flame-retardant properties were tested by the limiting oxygen index (LOI) (Yasuda Seiki Seisakusho Ltd, Japan) according to JIS K720-1976, with sheet dimensions of $120 \times 6.5 \times 3.2 \mathrm{~mm}$.

The UL-94 rating was tested according to the UL-94 (ASTMD635-12) with sheet dimensions of $125 \pm 5 \mathrm{~mm}$ long by $13.0 \pm 0.5 \mathrm{~mm}$ wide and minimum thickness, 3.0 $(-0.0+0.2) \mathrm{mm}$.

The combustion rate was measured by COMBUSTION RESISTANCE COD 6145000 according to the ASTM D757-77 standard. Specimen's dimensions were $3.17 \times 12.7 \times 121 \mathrm{~mm}^{3}$. The mechanical properties were measured on an INSTRON$5582100 \mathrm{KN}$ (USA) according to ISO 527-1993 with an extension speed of $5 \mathrm{~mm} / \mathrm{min}$. All data were the average of five 
TABLE 1: Level curing and time curing of the blend samples.

\begin{tabular}{|c|c|c|c|c|c|c|c|}
\hline $\begin{array}{l}\text { Epoxy Epikote } \\
240 \text { (phr) }\end{array}$ & $\begin{array}{c}\text { Epoxidised linseed } \\
\text { oil (phr) }\end{array}$ & $\begin{array}{l}\text { Gel time } \\
(\min )\end{array}$ & $\begin{array}{c}\text { Gel content } \\
(\%)\end{array}$ & $\begin{array}{c}\text { Epoxy Epikote } \\
240 \text { (phr) }\end{array}$ & $\begin{array}{c}\text { Epoxidised linseed } \\
\text { oil (phr) }\end{array}$ & $\begin{array}{l}\text { Gel time } \\
(\min )\end{array}$ & $\begin{array}{c}\text { Gel content } \\
(\%)\end{array}$ \\
\hline 100 & 0 & 72 & 89.05 & 45 & 55 & 120 & 24.76 \\
\hline 95 & 5 & 75 & 85.03 & 40 & 60 & 122 & 32.74 \\
\hline 90 & 10 & 76 & 83.83 & 35 & 65 & 132 & 20.06 \\
\hline 85 & 15 & 77 & 82.62 & 30 & 70 & 185 & 07.03 \\
\hline 80 & 20 & 79 & 84.63 & 25 & 75 & 686 & 07.49 \\
\hline 75 & 25 & 82 & 30.85 & 20 & 80 & 3362 & 05.06 \\
\hline 70 & 30 & 86 & 32.29 & 15 & 85 & - & - \\
\hline 65 & 35 & 95 & 44.10 & 10 & 90 & - & - \\
\hline 60 & 40 & 103 & 38.42 & 5 & 95 & - & - \\
\hline 55 & 45 & 114 & 42.21 & 0 & 100 & - & - \\
\hline 50 & 50 & 117 & 28.17 & & & & \\
\hline
\end{tabular}

independent measurements; the relative errors committed on each data were reported as well.

\section{Results and Discussion}

3.1. Investigation of Curing Process of Epoxy Epikote 240 Resin/ Epoxidised Linseed Oil Mixture with Other Ratios. Table 1 shows that the level curing of the EP/ELO mixture decreased and time curing increased with increasing of ELO phr. The sample with the EP/ELO ratio is 20/80, had 3362 minutes of time curing, and $5.06 \%$ of level curing. For samples with EP/ELO ratio from 15/85, time curing was not identified, and after 7 days, the 100 ELO phr was not cured. Based on results of time curing and level curing, we chose the samples with EP/ELO ratios 95/5, 90/10, 85/15, 80/20, and $75 / 25$ to study. Although the difference samples had suitable time curing, they were destroyed before measuring the mechanical properties because they had low mechanical properties. This showed that mixing ability and mechanical properties of materials decreased much when the content of ELO reached a limit.

\subsection{Effects of Content of Epoxidised Linseed Oil on Mechanical} Properties of Epoxy Epikote 240 Polymer. Table 2 shows that the sample with EP/ELO ratio 90/10 had the highest mechanical strength with $88.7 \mathrm{MPa}$ of flexural strength, 52.8 MPa of tensile strength, and 121.36 MPa of compressive strength. Compared with the initial epoxy polymer, the flexural strength increased by $2.24 \%$ and compressive strength lightly decreased because epoxidised linseed oil acted as a plasticized filler which improved the brittle property of the material.

When replacing partial synthetic polymers with different weights, the mechanical properties not only remain high compared with the synthetic polymers without mixing but also improve in some durability; in this case, the flexural strength increases, especially the Izod impact strength increases by $21.65 \%$; this is a good result compared with the works being studied by Samper et al. $[16,17]$. Thus, when replacing a part of fossil-derived substances with substances of biological origin (ELO), gel time and mechanical strength are maintained at a good level [18]
The impact of ELO content on the fire retardant property of EP/ELO materials is presented in Table 3. From Table 3, it is seen that the ELO content is more or less also affecting the flame-retardant property of the epoxy resin. When the content of ELO increases, the compatibility decreases, resulting in an unstable structure and causing the material fire retardation to decrease. Especially, the mixing ratio of $90 / 10 \mathrm{w} / \mathrm{w}$ is the ratio for good compatibility, high mechanical properties, and fire retardation compared to other ratios.

3.3. Investigation of Structure of Epoxy Epikote 240/Epoxidised Linseed Oil. In Figure 1, the results showed that the sample with EP/ELO ratio 90/10 had a homogenous structure and did not have a splitting phase. When the content of ELO increased, the splitting phase appeared and ELO particles precipitated like the $80 / 20$ sample that had ELO particles with nonuniform distribution and large size due to precipitation. The $90 / 10$ sample with 20.000 times of resolution showed that the average size of ELO particles was $0.5 \mu \mathrm{m}$ and they had uniform distribution and uniform size (Figure 2). The surface of ELO particles was covered by epoxy resin substrate. In this study, the blending process between epoxy and ELO is carried out at room temperature without the use of compatible auxiliaries. The high level of compatibility is shown by the FE-SEM measurement, which is better than those studied at high temperatures and using a common catalyst methylhexahydrophthalic anhydride (MHHPA) $[18,19]$.

3.4. Mechanical and Fire-Retardant Properties of Nanocomposite Materials Based on Epoxy Epikote 240 Combined with ELO with the Presence of Nanoclay I.30E, MWCNTs, and Retardants. Samples were made according to the mass ratios in Table 4.

Figure 3 shows the uniform distribution and good bonding of $\mathrm{Sb}_{2} \mathrm{O}_{3}$ particles in epoxy resin. Evidences show that after break of materials, $\mathrm{Sb}_{2} \mathrm{O}_{3}$ particles were still maintained in fracture surfaces and covered by epoxy E 240 resin (there was no space around the particles). MWCNTs were also distributed and interleaved with retardants (positioned by arrows). There is no agglomerate and clustered 
TABLE 2: Effects of epoxidized linseed oil on the mechanical strength of blend materials.

\begin{tabular}{|c|c|c|c|c|c|}
\hline $\begin{array}{l}\text { Samples, } \\
\text { EP/ELO, } \\
\text { phr }\end{array}$ & Tensile strength $(\mathrm{MPa})$ & Modulus (GPa) & Flexural strength $(\mathrm{MPa})$ & Compressive strength $(\mathrm{MPa})$ & Impact strength $(\mathrm{kJ} / \mathrm{m})$ \\
\hline 95 & 44.90 & 1.30 & 88.06 & 117.18 & 45.13 \\
\hline 90 & 52.80 & 1.40 & 88.70 & 121.36 & 49.92 \\
\hline 85 & 42.29 & 1.26 & 82.13 & 91.52 & 50.67 \\
\hline 80 & 36.64 & 1.22 & 77.40 & 124.82 & 47.45 \\
\hline 75 & 10.92 & 0.94 & 56.45 & 120.98 & 32.01 \\
\hline
\end{tabular}

TABLE 3: Effect of E240/ELO epoxy ratios on mechanical and flame-retardant properties of the materials.

\begin{tabular}{lcccc}
\hline No. & \multicolumn{2}{c}{ Samples $(\mathrm{EP} / \mathrm{ELO})(\mathrm{phr})$} & LOI $\left(\mathrm{vol} \% \mathrm{O}_{2}\right)$ & $\mathrm{HB}(\mathrm{mm} / \mathrm{min})$ \\
\hline 1 & 100 & 0 & 20.6 & 28.41 \\
2 & 95 & 5 & 20.2 & 30.30 \\
3 & 90 & 10 & 21.5 & 32.35 \\
4 & 85 & 15 & 20.2 & 34.50 \\
5 & 80 & 20 & 19.7 & 35.23 \\
\hline
\end{tabular}
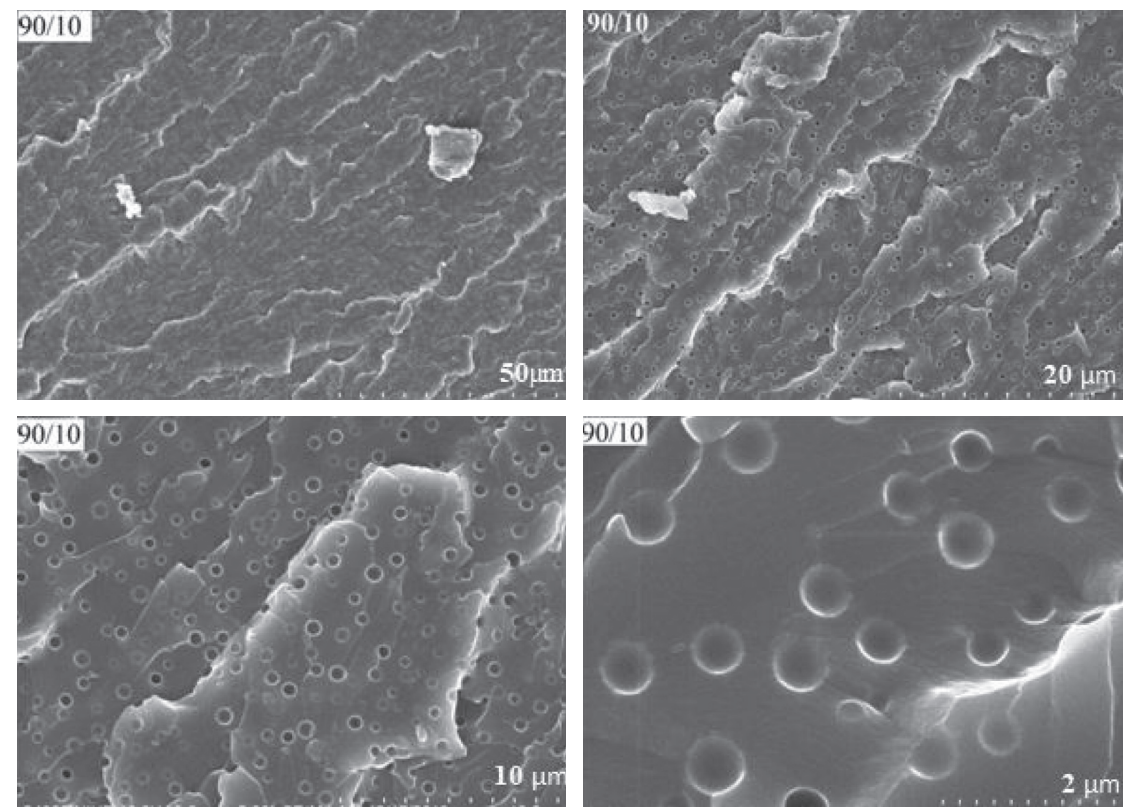

FIGURE 1: FE-SEM of the sample epoxy Epikote 240/epoxidised linseed oil images with ratio 90/10 phr (with other resolutions).
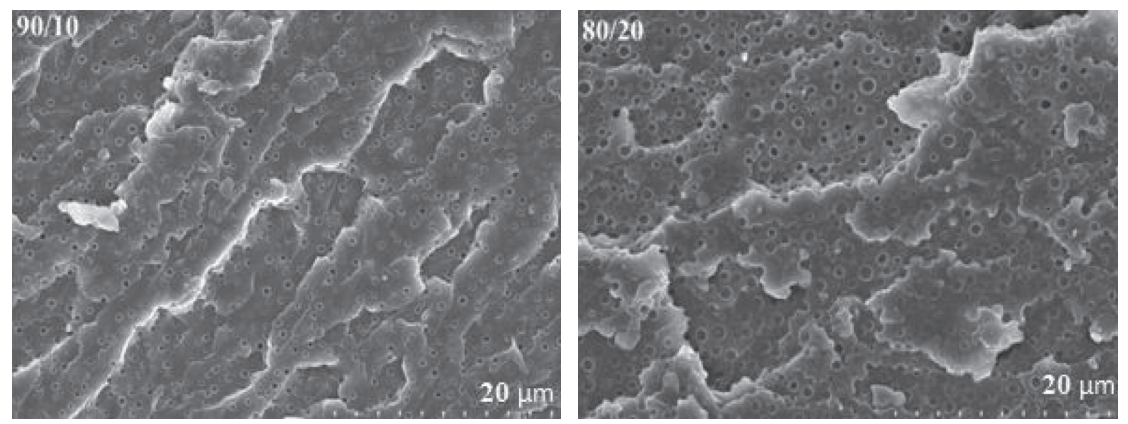

Figure 2: FE-SEM of the sample epoxy Epikote 240/epoxidised linseed oil (EP/ELO) images with ratios 90/10 and 80/20 phr. 
TABLE 4: Taguchi orthogonal array of designed experiments based on the coded levels.

\begin{tabular}{|c|c|c|c|c|c|}
\hline Trial & Material & $\begin{array}{l}\text { MWCNT content } \\
(\mathrm{wt} \%)\end{array}$ & $\begin{array}{c}\text { Nanoclay content } \\
(\mathrm{wt} \%)\end{array}$ & $\begin{array}{c}\mathrm{Sb}_{2} \mathrm{O}_{3} / \text { chlorinated paraffin } \\
(\mathrm{phr})\end{array}$ & $\begin{array}{l}\text { Epoxidised linseed oil } \\
\text { (phr) }\end{array}$ \\
\hline 1 & NC01 (neat epoxy) & - & - & - & 10 \\
\hline 2 & $\mathrm{NCO} 2$ & - & 2 & $9 / 11$ & 10 \\
\hline 3 & $\mathrm{NC03}$ & 0.02 & - & $9 / 11$ & 10 \\
\hline 4 & $\mathrm{NC0} 4$ & 0.02 & 2 & - & - \\
\hline 5 & NC05 & 0.02 & 2 & - & 10 \\
\hline 6 & NC06 & 0.02 & 2 & $9 / 11$ & - \\
\hline 7 & NC07 & 0.02 & 2 & $9 / 11$ & 10 \\
\hline
\end{tabular}

NC: nanocomposite.
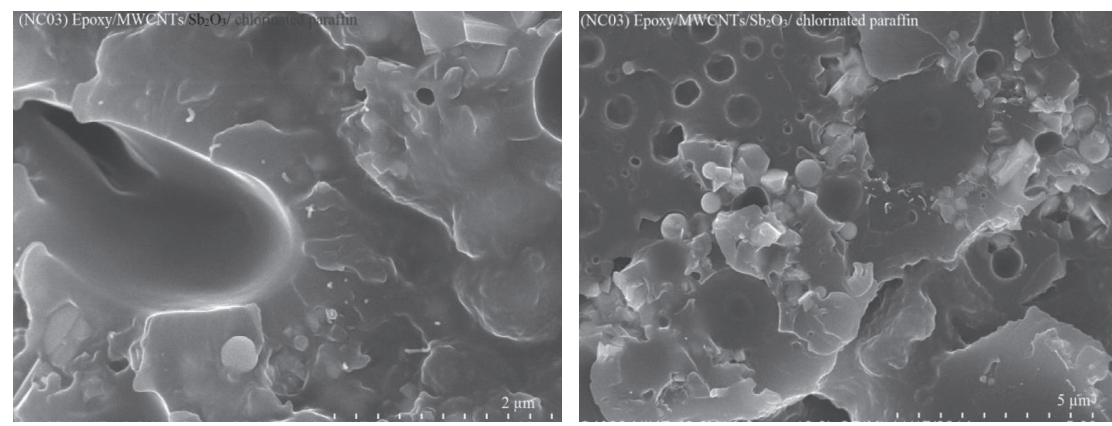

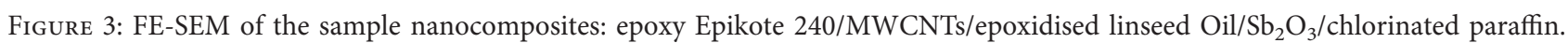

phenomenon, showing the good combination of MWCNTsretardants-epoxy resin E240. The distribution of MWCNTs and ELO in epoxy resin E 240 shown in Figure 4 was quite nice. In Figure 5, FE-SEM image shows that MWCNTs and retardants were distributed uniformly in the epoxy background (positioned by arrows) as well as their good sticking and combination with epoxy resin E 240; the resin still covered $\mathrm{Sb}_{2} \mathrm{O}_{3}$ and MWCNTs after breaking the samples by pulling. Figures 5 and 6 also prove the uniform distribution of nanoclay I.30E, MWCNTs, and retardants in epoxy resin E 240 as well as the good sticking between them.

The XRD diagram of epoxy E 240-based nanocomposite materials is present in nanoclay, MWCNTs, and flame retardants, as shown in Figure 7. From Figure 7, nanoclay I.30E has been separated and alternated in epoxy E 240. For materials with flame-retardant surface, there are some peaks in the XRD diagram due to the composition of $\mathrm{Sb}_{2} \mathrm{O}_{3}$. The XRD pattern reveals that the organoclay gets delaminated in the epoxy matrix.

ELO and chlorinated paraffins make epoxy resin E 240 more flexible. Thus, Table 5 shows that the impressive strength and tensile strength of samples decreased, but the flexural strength and impact strength strongly increased when ELO and chlorinated paraffins are added. A loose outer garment is worn over a swimsuit or exercise outfit. When adding MWCNTs and nanoclay I.30E into epoxy resin E 240, the mechanical strength was significantly changed. The decrease of the mechanical strength of materials when adding retardants was offset by advantages of MWCNTs and nanoclay I.30E.

In parallel with the above processes, MWCNTs were uniformly distributed in epoxy resin forming ash layers covering the material surface and preventing the contact between oxygen and the materials, limiting the development of flame. The ash layers uniformly spread in the material surface and made the samples not dripping when burning and improved the flame-retardant capability of epoxy resin. The combination of the flame-retardant mechanisms improved the flame-retardant capability of materials (Table 6). It can be said that the distribution ability of retardants in binders is more uniform, and the mechanical and retardant properties of materials improved. In this work, ELO has made E 240 epoxy resin more and more flexible, overcoming the brittle disadvantages of primary resins. Hence, the mechanical strength presented in Table 5 has shown that the compressive strength and tensile strength decrease slightly; however, the flexural strength and tensile strength increase at a high level. The assessment of fire resistance of nanocomposite materials (Table 6) has shown that the level of fire resistance reaches $\mathrm{V}-1$ for materials in the presence ELO. Obviously, the role of ELO is very important, which is a substance of biological origin to replace a part of fossil raw materials (epoxy resin), as it enhances the mechanical properties and flame-retardant properties to a good level compared with the prescribed standards. In addition, in this study, the material fabrication conditions were carried out under normal conditions and without the use of any other catalysts; the mechanical properties, flame-retardant properties, and compatibility are quite high compared with those of other studies $[15,20,21]$. The morphologies of residues after ignition by alcohol burner were investigated by SEM in Figure 8. It is worth noting that turning it into a char flake has a continuous surface under SEM in Figure8. This demonstrates that ELO has more or less impact on the 

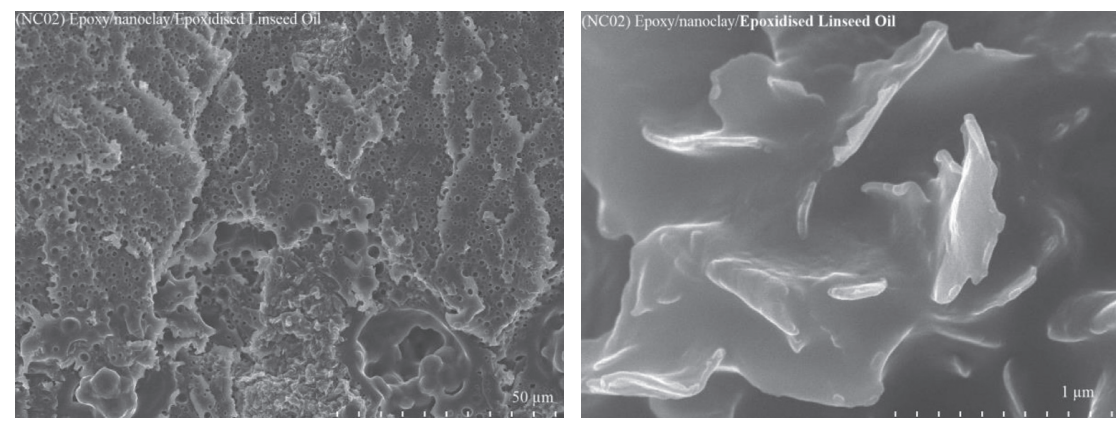

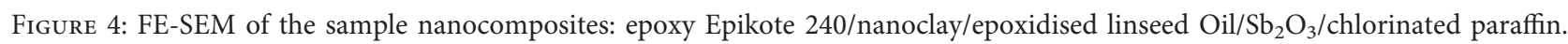
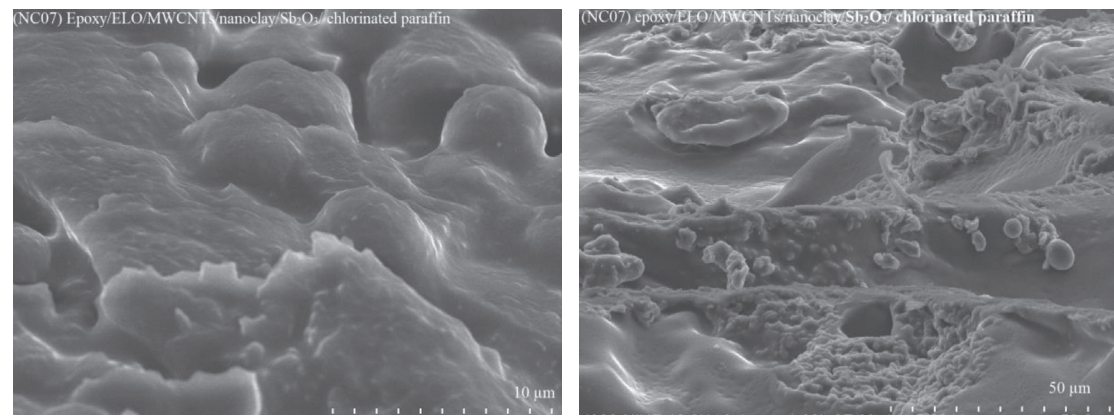

FIGURE 5: FE-SEM of the sample nanocomposites: epoxy Epikote 240/nanoclay/MWCNTs/epoxidised linseed oil/Sb $\mathrm{O}_{3} / \mathrm{chlorinated}$ paraffin.
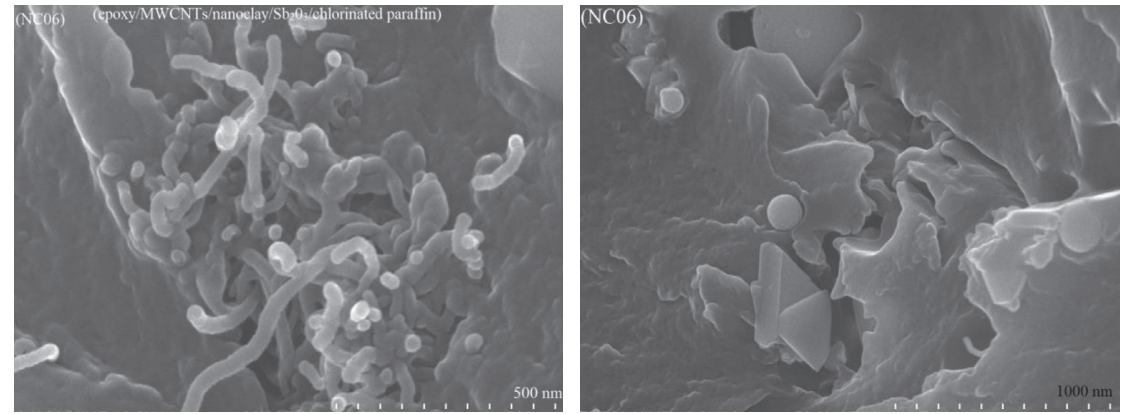

FIGURE 6: FE-SEM of the sample nanocomposites: epoxy Epikote 240/MWCNTs/nanoclay/ $\mathrm{Sb}_{2} \mathrm{O}_{3} /$ chlorinated paraffin.

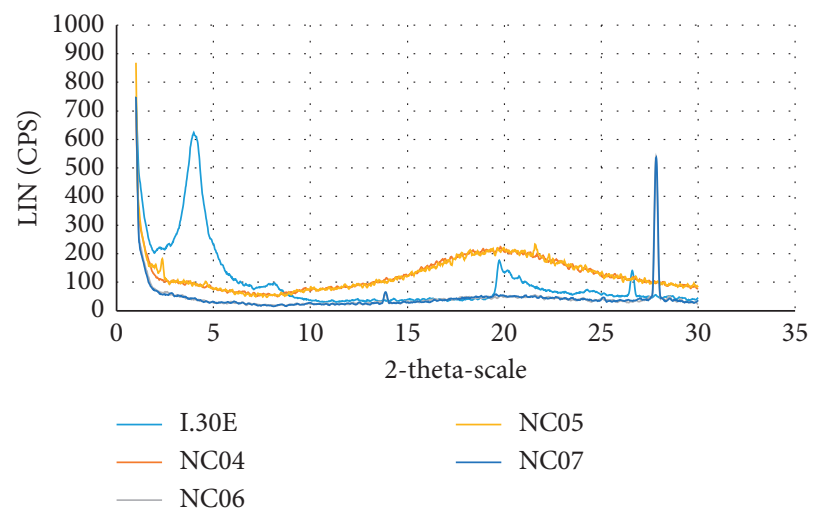

FIGURE 7: XRD diagram of materials I.30E, MWCNTs/nanoclay/epoxy (NC04), MWCNTs/nanoclay/ELO/epoxy (NC06), MWCNTs/ nanoclay/ $\mathrm{Sb}_{2} \mathrm{O}_{3} /$ chlorinated paraffin/epoxy (NC05), and MWCNTs/nanoclay/ELO/Sb $\mathrm{O}_{3} /$ chlorinated paraffin/epoxy (NC07). 
TABLE 5: Effects of epoxidized linseed oil to the mechanical strength of blend materials.

\begin{tabular}{lccccc}
\hline Trial & Material & Tensile strength $(\mathrm{MPa})$ & Flexural strength $(\mathrm{MPa})$ & Compressive strength $(\mathrm{MPa})$ & ${\text { Impact strength }\left(\mathrm{kJ} / \mathrm{m}^{2}\right)}^{2}$ \\
\hline 1 & NC01 (neat epoxy) & 5590 & 8675 & 156.08 & 7.11 \\
2 & NC02 & 60.03 & 99.60 & 170.03 & 14.94 \\
3 & NC03 & 70.34 & 113.40 & 219.10 & 21.16 \\
4 & NC04 & 95.50 & 115.45 & 187.03 & 22.30 \\
5 & NC05 & 88.80 & 118.90 & 190.57 & 22.49 \\
6 & NC06 & 86.23 & 115.76 & 189.25 & 23.14 \\
7 & NC07 & 85.45 & 116.32 & & 24.37 \\
\hline
\end{tabular}

TABLE 6: Results for flammability tests (reaction to small flame), oxygen index (OI), and UL 94 for nanocomposites.

\begin{tabular}{lcccc}
\hline Material & LOI $\left(\mathrm{vol} \% \mathrm{O}_{2} \pm 2 \sigma\right)$ & Combustion rate $(\mathrm{mm} / \mathrm{min})$ & UL94 HB $(\mathrm{mm} / \mathrm{min})$ & UL94V \\
\hline NC01 (neat epoxy) & $20.6 \pm 0.3$ & 28.41 & Not rated (NR) & Not rated (NR) \\
NC02 & 25.9 & 18.79 & 19.90 & Not rated (NR) \\
NC03 & 25.4 & 18.07 & 18.60 & Not rated (NR) \\
NC04 & 25.0 & 20.05 & 12.90 & Not rated (NR) \\
NC05 & 25.9 & 16.08 & 10.09 & Not rated (NR) \\
NC06 & 29.8 & 11.34 & 10.15 & V1 \\
NC07 & 29.8 & 13.07 & V1 \\
\hline
\end{tabular}
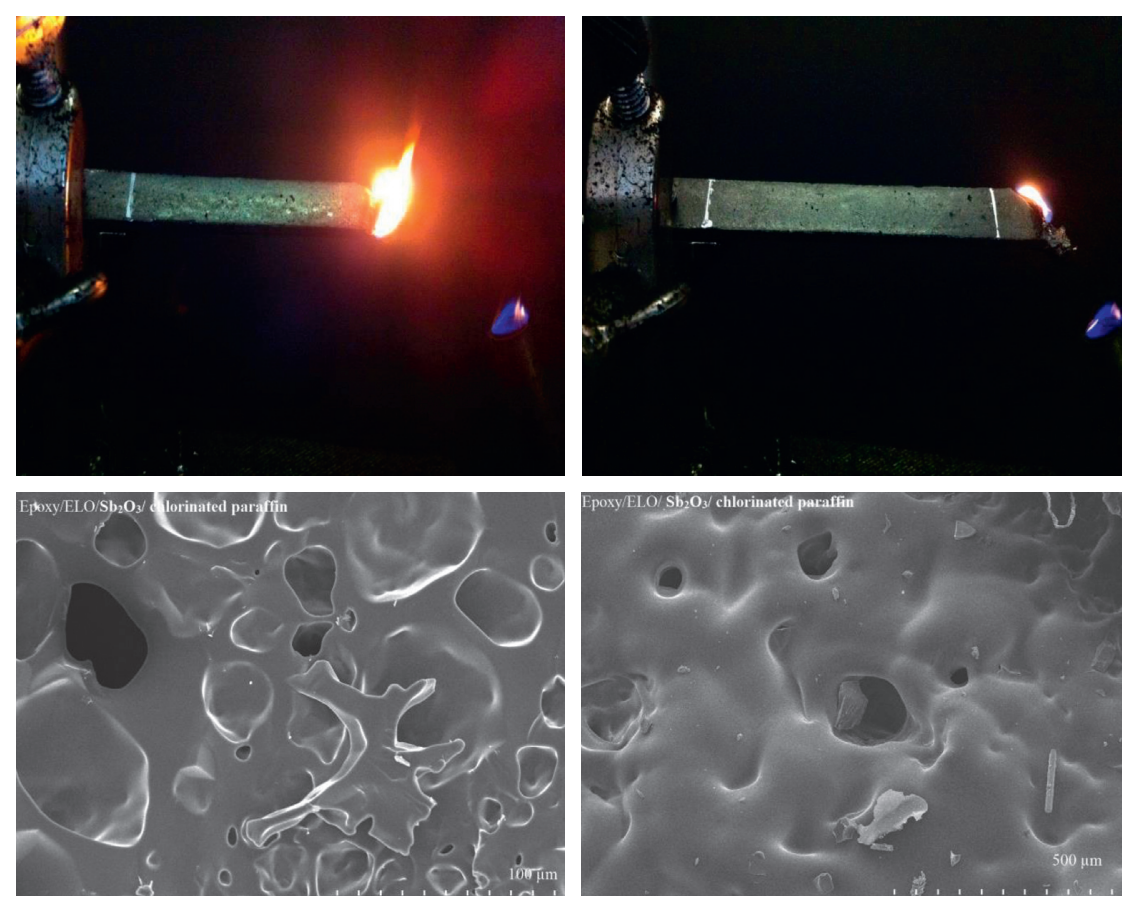

FIGURE 8: SEM morphologies of the residues of composite epoxy/epoxidised linseed oil/ $\mathrm{Sb}_{2} \mathrm{O}_{3} /$ chlorinated paraffin from ignition by an alcohol burner (UL 94HB).

flame-retardant property of the material clearly expressed in the FE-SEM image of the material surface after the fireretardant test.

\section{Conclusions}

With this study, we can conclude that the nano/epoxy/ELO composites with different contents of ELO have been successfully modulated by mechanical methods and ultrasonic vibrations. XRD, FE-SEM, and studies on mechanical strength and fire resistance have confirmed the significant improvement in mechanical properties and fire resistance of nanocomposites. ELO can be used directly as a plasticizer to improve the flexibility, elasticity, and stability of heat-resistant polymers while being biodegradable and environment-friendly. ELO does not react with epoxide at room temperature; hence, ELO cannot be used in large amounts. ELO can only be added in small amounts (10\% by weight) to increase the toughness. The appropriate optimal content of ELO in epoxy resin E 240 is 10\% by weight of epoxy E 240 
combination. UL94 and LOI tests showed a significant improvement in fire resistance of MWCNTs (0.02 wt.\%)/ nanoclay (2 wt.\%)/ELO (10 phr)/epoxy nanocomposite compared with pristine epoxy. So, the resulting system provides a potential high-performance material for many advanced applications.

\section{Data Availability}

The data used to support the findings of this study are available from the corresponding author upon request (https://anhnt@haui.edu.vn).

\section{Conflicts of Interest}

The authors declare that there are no conflicts of interest regarding the publication of this paper.

\section{Acknowledgments}

The authors wish to thank the Faculty of Chemical Technology, Hanoi University of Industry, for funding this work.

\section{References}

[1] A. Kadam, M. Pawar, O. Yemul, V. Thamke, and K. Kodam, "Biodegradable biobased epoxy resin from karanja oil," Polymer, vol. 72, pp. 82-92, 2015.

[2] W. S. Chow, S. G. Tan, Z. Ahmad, K. H. Chia, N. S. Lau, and K. Sudesh, "Biodegradability of epoxidized soybean oil based thermosets in compost soil environment," Journal of Polymers and the Environment, vol. 22, no. 1, pp. 140-147, 2014.

[3] M.-K. Seo and S.-J. Park, "A kinetic study on the thermal degradation of multi-walled carbon nanotubes-reinforced poly(propylene) composites," Macromolecular Materials and Engineering, vol. 289, no. 4, pp. 368-374, 2004.

[4] S.-O. Lee, S.-H. Choi, S. H. Kwon, K.-Y. Rhee, and S.-J. Park, "Modification of surface functionality of multi-walled carbon nanotubes on fracture toughness of basalt fiber-reinforced composites," Composites Part B: Engineering, vol. 79, pp. 47-52, 2015.

[5] J.-L. Audic, L. Lemiègre, and Y.-M. Corre, "Thermal and mechanical properties of a polyhydroxyalkanoate plasticized with biobased epoxidized broccoli oil," Journal of Applied Polymer Science, vol. 131, no. 6, 2014.

[6] S. G. Tan, Z. Ahmad, and W. S. Chow, "Interpenetrating polymer network structured thermosets prepared from epoxidized soybean oil/diglycidyl ether of bisphenol A," Polymer International, vol. 63, no. 2, pp. 273-279, 2014.

[7] S.-J. Park, F.-L. Jin, and J.-R. Lee, "Effect of biodegradable epoxidized castor oil on physicochemical and mechanical properties of epoxy resins," Macromolecular Chemistry and Physics, vol. 205, no. 15, pp. 2048-2054, 2004.

[8] S.-J. Park, F.-L. Jin, and J.-R. Lee, "Synthesis and thermal properties of epoxidized vegetable oil," Macromolecular Rapid Communications, vol. 25, no. 6, pp. 724-727, 2004.

[9] H. Miyagawa, R. J. Jurek, A. K. Mohanty, M. Misra, and L. T. Drzal, "Biobased epoxy/clay nanocomposites as a new matrix for CFRP," Composites Part A: Applied Science and Manufacturing, vol. 37, no. 1, pp. 54-62, 2006.

[10] J. Alam, M. Alam, M. Raja, Z. Abduljaleel, and L. Dass, "MWCNTs-Reinforced epoxidized linseed oil plasticized polylactic acid nanocomposite and its electroactive shape memory behaviour," International Journal of Molecular Sciences, vol. 15, no. 11, pp. 19924-19937, 2014.

[11] G. Das and N. Karak, "Thermostable and flame retardant Mesua ferrea L. seed oil based non-halogenated epoxy resin/ clay nanocomposites," Progress in Organic Coatings, vol. 69, no. 4, pp. 495-503, 2010.

[12] S. M. Kabeb, A. Hassan, Z. Mohamad, Z. Sharer, M. Mokhtar, and F. Ahmad, "Exploring the effects of nanofillers of epoxy nanocomposite coating for sustainable corrosion protection," Chemical Engineering Transactions, vol. 72, pp. 121-126, 2019.

[13] T. A. Nguyen, Q. T. Nguyen, and T. P. Bach, "Mechanical properties and flame retardancy of epoxy resin/nanoclay/ multiwalled carbon nanotube nanocomposites," Journal of Chemistry, vol. 2019, Article ID 3105205, 9 pages, 2019.

[14] T. A. Nguyen, Q. T. Nguyen, X. C. Nguyen, and V. H. Nguyen, "Study on fire resistance ability and mechanical properties of composites based on Epikote 240 epoxy resin and thermoelectric fly ash: an ecofriendly additive," Journal of Chemistry, vol. 2019, Article ID 2635231, 8 pages, 2019.

[15] N. T. Anh, "Mechanical and flame-retardant properties of exoxy Epikote 240/epoxidized linseed oil composites using fiber-glass," Mehran University Research Journal of Engineering and Technology, vol. 39, no. 1, pp. 9-20, 2020.

[16] M. D. Samper, J. M. Ferri, A. Carbonell-Verdu, R. Balart, and O. Fenollar, "Properties of biobased epoxy resins from epoxidized linseed oil (ELO) crosslinked with a mixture of cyclic anhydride and maleinized linseed oil," Express Polymer Letters, vol. 13, no. 5, pp. 407-418, 2019.

[17] V. Fombuena, R. Petrucci, F. Dominici, A. Jordá-Vilaplana, N. Montanes, and L. Torre, "Maleinized linseed oil as epoxy resin hardener for composites with high bio content obtained from linen byproducts," Polymers, vol. 11, no. 2, p. 301, 2019.

[18] K. Thiele, N. Eversmann, A. Krombholz, and D. PufkyHeinrich, "Bio-based epoxy resins based on linseed oil cured with naturally occurring acids," Polymers, vol. 11, no. 9, p. 1409, 2019.

[19] E. Ramon, C. Sguazzo, and P. Moreira, "A review of recent research on bio-based epoxy systems for engineering applications and potentialities in the aviation sector," Aerospace, vol. 5, no. 4, p. 110, 2018.

[20] S. K. Sahoo, V. Khandelwal, and G. Manik, "Development of toughened bio-based epoxy with epoxidized linseed oil as reactive diluent and cured with bio-renewable crosslinker," Polymers for Advanced Technologies, vol. 29, no. 1, pp. 565574, 2017.

[21] E. Vigueras Santiago, M. A. Camacho López, J. E. Moreno Marcelino, and S. Hernández López, "Dispersion of MWNT under different solvents and its effect on the electrical properties of cured-epoxidized linseed oil composites," International Journal of Composite Materials, vol. 8, no. 1, pp. 10-17, 2018. 